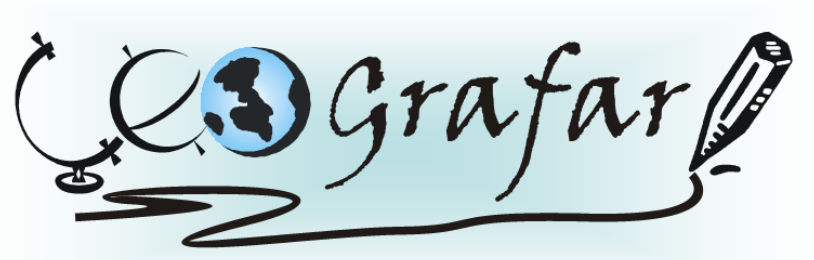

Revista Eletrônica do Programa de Pós-Graduação em Geografia - UFPR

\title{
ESTUDO DE METODOLOGIAS PARA IDENTIFICAÇÃO DE FORMAS DE VERTENTES NA BACIA DO RIO CURRALINHO - REGIÃO METROPOLITANA DE CURITIBA/PR
}

\section{STUDY OF METHODOLOGIES FOR IDENTIFICATION OF FORMS OF SLOPES IN RIVER BASIN CURRALINHO - METROPOLITAN AREA CURITIBA/PR}

(Recebido em 20.01.2013; Aceito em 25.02.2013)

\author{
Carlos Henrique Sopchaki \\ Doutorando em Geografia - UFPR \\ Bolsista CAPES \\ Curitiba, PR, Brasil \\ e-mail:carlos.sop@uol.com.br
}

Tony Vinicius Moreira Sampaio Prof ${ }^{\circ}$ Dro ${ }^{\circ}$ do Departamento de Geografia - UFPR

Curitiba, PR, Brasil

e-mail: tonysampaio@ufpr.br

\begin{abstract}
Resumo
O mapeamento geomorfológico é utilizado em larga escala para fins de planejamento territorial e análises de cunho ambiental, no entanto, há lacunas e conflitos no processo de produção dos mapas. Um dos problemas refere-se ao conceito de vertentes e à metodologia para classificação das mesmas. Embora as vertentes sejam elementos tridimensionais, há basicamente, duas metodologias para identificação e delimitação das mesmas: uma baseada na análise de perfis bidimensionais; e outra baseada na análise de suas características geométricas. Ambas as metodologias demonstram algum grau de subjetividade em alguma etapa e/ou produzem resultados que não representam a vertente em sua totalidade, mas sim fragmentos de vertentes. Devido aos problemas conceituais e metodológicos, diferentes pesquisadores podem chegar a resultados diferentes, mapeando uma área em comum. $O$ objetivo desta pesquisa foi o de analisar a classificação das vertentes em diferentes mapeamentos geomorfológicos em uma mesma área. Os
\end{abstract}


resultados demonstraram que houve divergência entre os mapeamentos, evidenciando assim, o problema conceitual e metodológico no que concerne às vertentes.

Palavras-Chave: formas de vertente, perfil de curvatura, Rio Curralinho, TOPODATA.

\begin{abstract}
The geomorphological mapping is used on a large scale for territorial planning and analysis of environmental nature, however, there are gaps and conflicts in the production of maps. One of the problems relates to the concept of slopes and the method for their classification. Although the slopes are three-dimensional elements, there are basically two methods for identifying and delimiting the same: one based on the analysis of two-dimensional profiles, and another based on an analysis of its geometric characteristics. Both methods show some degree of subjectivity in some stage and / or produce results that do not represent a slope in its entirety, but fragments of slopes. Due to conceptual and methodological problems, different researchers can get to different results, mapping an area in common. The objective of this research was to analyze the classification of the slopes in different geomorphological mapping in the same area. The results showed that there was divergence between the mappings, thus underlining the conceptual and methodological problems in what concerns the slopes.
\end{abstract}

Keywords: slope forms, profile curvature, River Curralinho, TOPODATA.

\title{
Introdução
}

O mapeamento geomorfológico, embora seja utilizado em larga escala para fins de planejamento territorial e ambiental, possui lacunas e conflitos no processo de produção dos mapas, por conta da dificuldade de se obter critérios metodológicos e conceituais únicos ou padronizados, conforme destaca Argento (2003).

Uma das dificuldades observadas no processo de mapeamento geomorfológico refere-se à definição e delimitação das vertentes, as quais, segundo Young (1972), fornecem a base para os mapeamentos geomorfológicos e constituem um dos ramos de estudo da geomorfologia tanto no que se refere à forma, como processos subjacentes associados.

Conforme Penteado (1978), caracterizar geometricamente uma vertente é um processo complexo, pois seus declives são irregulares e raramente podem ser 
descritas por equações matemáticas únicas. Neste sentido, a autora afirma que os geomorfólogos têm se preocupado mais com a descrição empírica dos declives, carecendo ainda de teorias válidas que embasem tais estudos.

Devido à importância do elemento vertente na paisagem, no mapeamento geomorfológico e na análise ambiental em geral, faz-se necessário estudos a fim de demonstrar os problemas conceituais e metodológicos no que se refere à identificação e delimitação de vertentes.

Buscando contribuir com o tema em questão, esta pesquisa aborda a geometria das vertentes mapeadas por diferentes pesquisadores em uma mesma região.

Neste sentido o objetivo deste trabalho é o de fazer uma análise entre dois mapeamentos geomorfológicos de uma mesma área, com o propósito de verificar como foram mapeadas as vertentes. Para tanto, esta pesquisa se propôs a comparar os padrões de curvatura vertical elaborados pelo Instituto Nacional de Pesquisas Espaciais - INPE, através do Projeto Topodata (2008), com o mapeamento feito por Boiko (2004) na Bacia Hidrográfica do Rio Curralinho (BHRC).

\section{Área de estudo}

A Bacia Hidrográfica do Rio Curralinho, a qual foi objeto de área de estudo para fins de mapeamento geomorfológico e fragilidade ambiental por Boiko (2004), está localizada entre os municípios de Quatro Barras e Piraquara (Figura 1), na Região Metropolitana de Curitiba. 


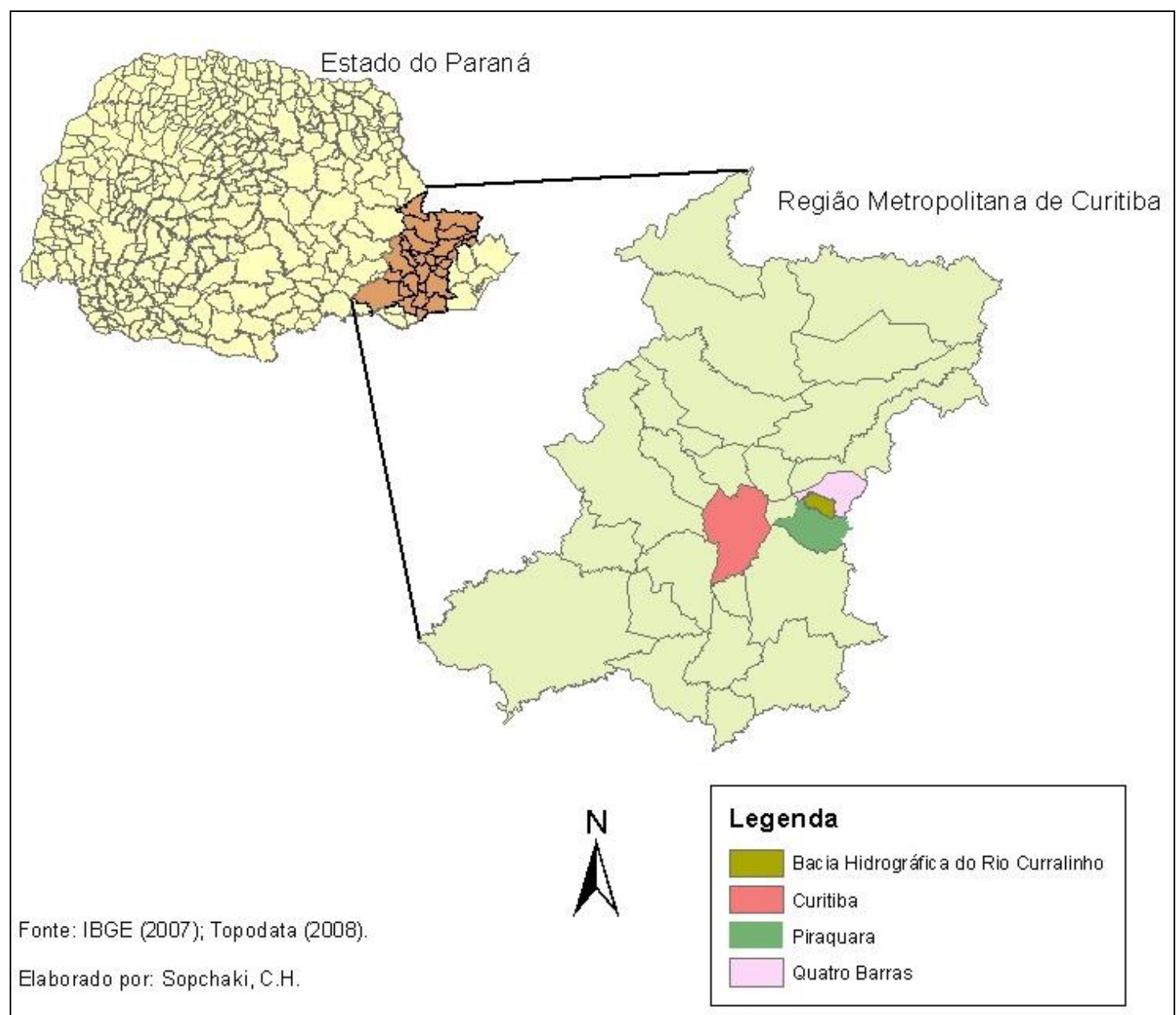

Figura 1 - Localização da Bacia Hidrográfica do Rio Curralinho Fonte: Organizado pelo autor, 2011.

De acordo com SUDERSHA (2000) e Boiko (2004), na BHRC estão presentes cinco litologias: o Complexo Gnáisso Migmatítico (em partes do terço médio e superior), o Complexo Granítico (ocupando parte do terço superior), o Complexo Granítico-Gnáissico (nas maiores altitudes da BHRC), a Formação Guabirotuba (porções do terço médio e inferior), os Aluviões Antigos e Aluviões Atuais (ambos em porções do trecho inferior).

No que concerne à geomorfologia, a BHRC tem suas nascentes na Formação Serra do Mar e exutório no Primeiro Planalto de Curitiba. Boiko (op. Cit.), afirma que as cotas altimétricas da BHRC estão entre $1420 \mathrm{~m}$ e $880 \mathrm{~m}$. Segundo a autora, $43 \%$ da área da bacia tem declividades entre 0 e 6\%, 17\% da área está entre 6 e 12\%, 15\% está inserida na classe de 12 a 20\%, 8\% da área enquadra-se na classe de 20 a $30 \%$ e $17 \%$ da área da bacia tem declividades maiores que $30 \%$. 
Com relação à pedologia da $\mathrm{BHRC}$, de acordo com JACOBS (2000), a bacia apresenta Afloramentos Rochosos e Solos Litólicos, Cambissolos, Latossolos, Solos Hidromórficos e Organossolos.

\section{Conceitos e incongruências}

Finlayson e Statham $\left(1980^{1}\right)$ apud Dikau et al. (2006) afirmam que as vertentes constituem um elemento básico para todas as paisagens e um componente fundamental para os sistemas geomorfológicos. Contudo, segundo Dikau et al. (op. cit.), "há uma ausência surpreendente de qualquer definição precisa" sobre vertentes.

Christofoletti (1980) e Bigarella et al. (2007) conceituam a vertente centrados na análise da forma, apresentando a mesma como sendo uma superfície inclinada, não horizontal, sem qualquer implicação genética ou de posicionamento, definindo a superfície propriamente dita, bem como sua declividade.

Osterkamp (2008) afirma que vertentes são quaisquer superfícies inclinadas da Terra e como medidas geomórficas podem ser expressas geralmente em graus a partir da horizontal.

Veloso (2002) apresentou proposta de classificação das vertentes a partir da análise de sua forma geométrica, sendo as mesmas, elementos da superfície terrestre inclinados em relação à horizontal que podem ser descritos a partir da variabilidade do seu grau de curvatura, caracterizado por perfis ou segmentos de perfis.

Desta forma, a análise da inclinação (expressa por ângulo ou gradiente) permite a classificação das vertentes (em perfis de curvatura) em retilíneas, quando segmentos ou partes das vertentes apresentam ângulo constante e, em curvas, quando apresentam ângulo variável. Estas últimas podem ainda ser classificadas como côncavas ou convexas de acordo com a direção da curvatura e não podem ser descritas por um simples ângulo.

\footnotetext{
${ }^{1}$ FINLAYSON, B; STATHAM, I. Hillslope Analysis, London: Butterworth, 1980
} 
A proposta de Veloso (2002) considera como metodologia para análise e classificação das vertentes o emprego de perfis bidimensionais, ou seja, linhas traçadas sobre o terreno que descrevem a inclinação da vertente em um determinado trecho.

Segundo Christofoletti (1980) e Summerfield (1991), esta metodologia é a mais utilizada para a análise das formas das vertentes, tendo sido proposta inicialmente por Savigear $(1956,1967)$ e por Young $(1964,1971)$.

Young (1971) propôs que os perfis fossem subdivididos em unidades retilíneas, côncavas e convexas, metodologia que tem o mérito de simplificar 0 processo de classificação e que tem produzido resultados significantes na delimitação das vertentes. No entanto, o autor salientou que este processo implica em diferentes níveis de subjetividades que podem levar diferentes autores a encontrar diferentes resultados, mesmo a partir da análise de uma base única de dados.

A fim de se aplicar a metodologia proposta por Young (op. cit), foram traçados três perfis aleatórios em uma vertente na Bacia Hidrográfica do Rio Curralinho (Figura 2). Os resultados foram perfis distintos, nenhum dos três é uniforme, no entanto apresentam formas predominantes. O 'perfil 1' (Figura 3) tem predomínio de forma côncava, no 'perfil 2' (Figura 4) predomina a forma convexa e no 'perfil 3' (Figura 5) predomina a forma retilínea. 


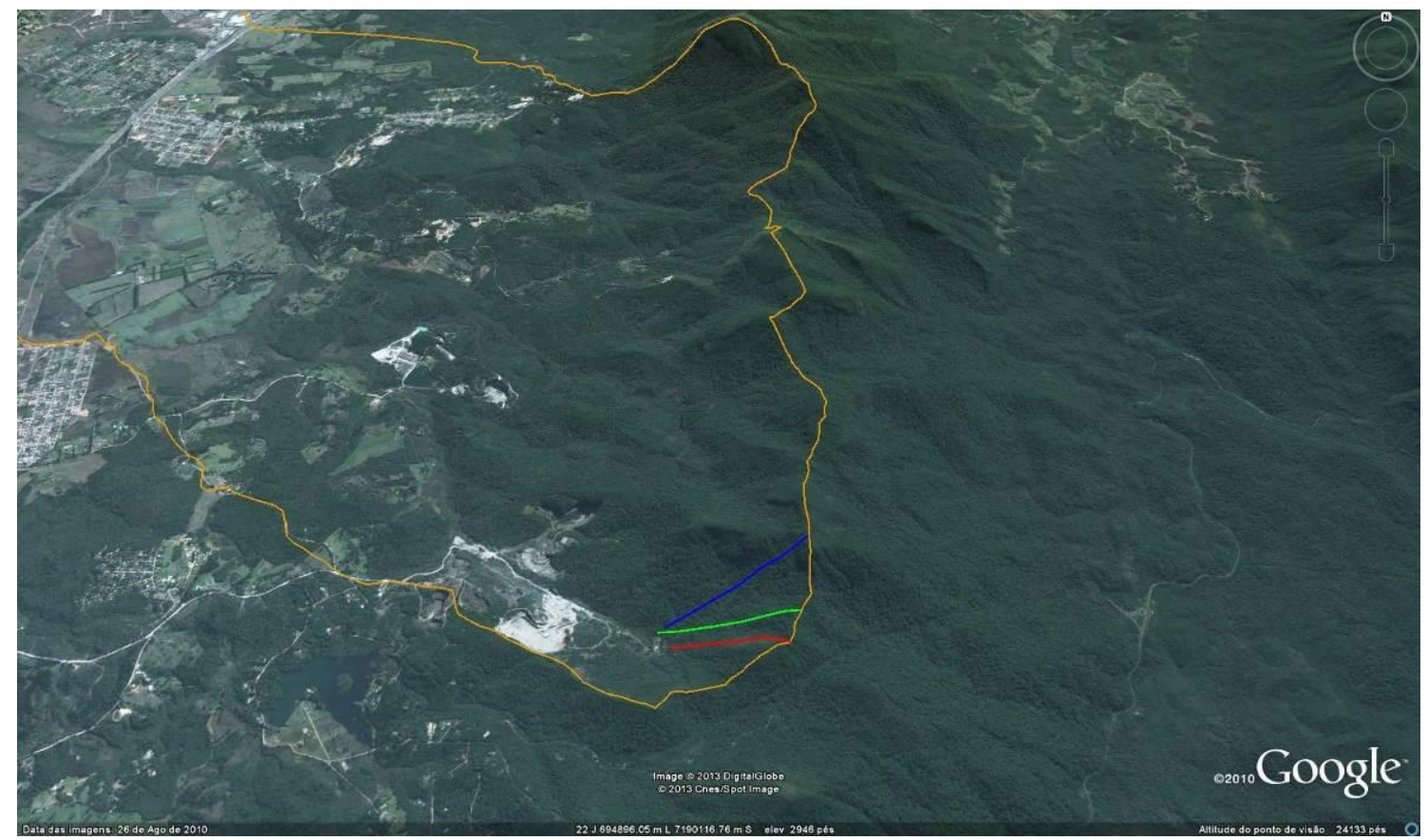

Figura 2 - Vertente na Bacia do Rio Curralinho com três perfis aleatórios

Fonte: Google Earth, adaptado pelo autor.

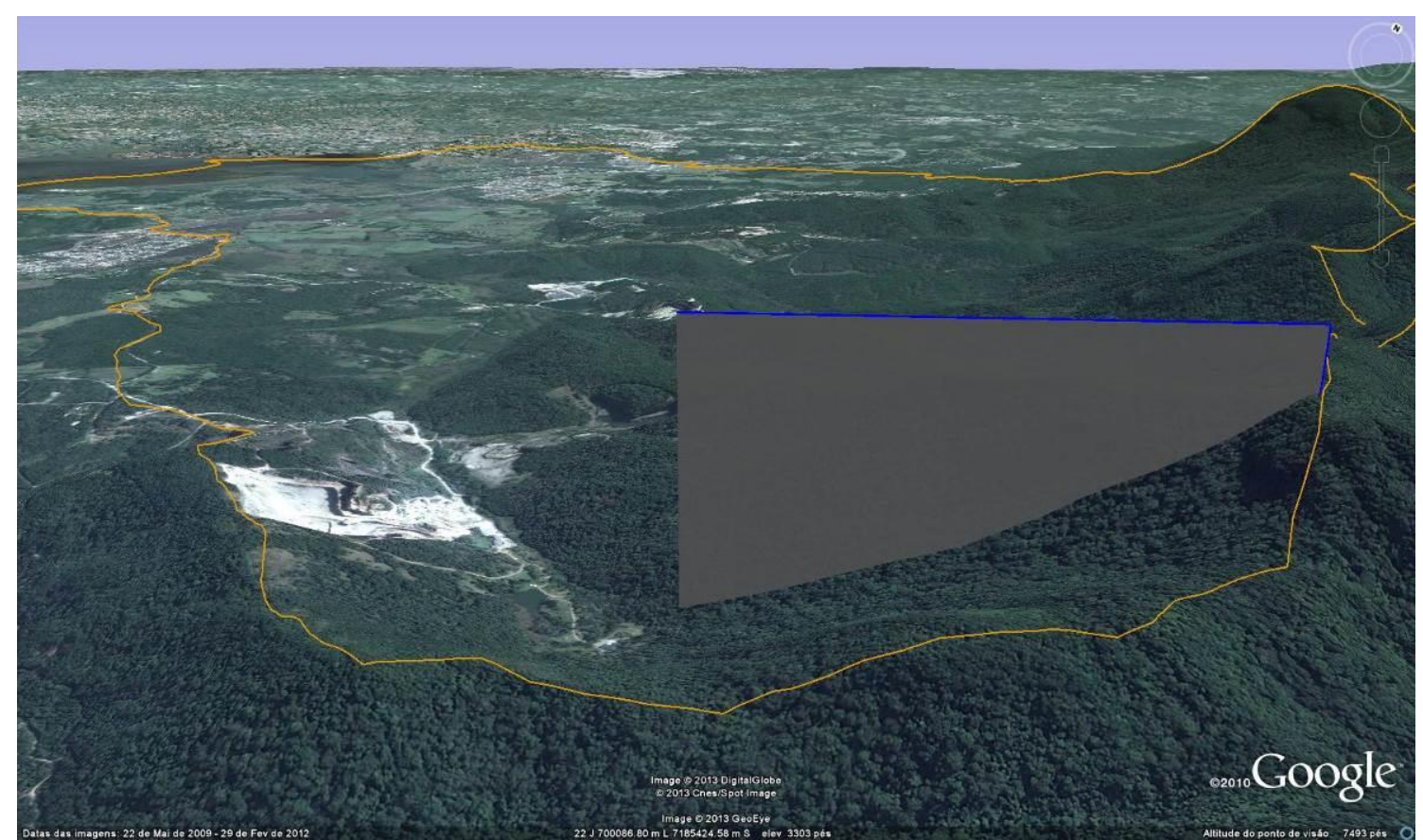

Figura 3 - 'Perfil 1' - Vertente na Bacia do Rio Curralinho

Fonte: Google Earth, adaptado pelo autor. 


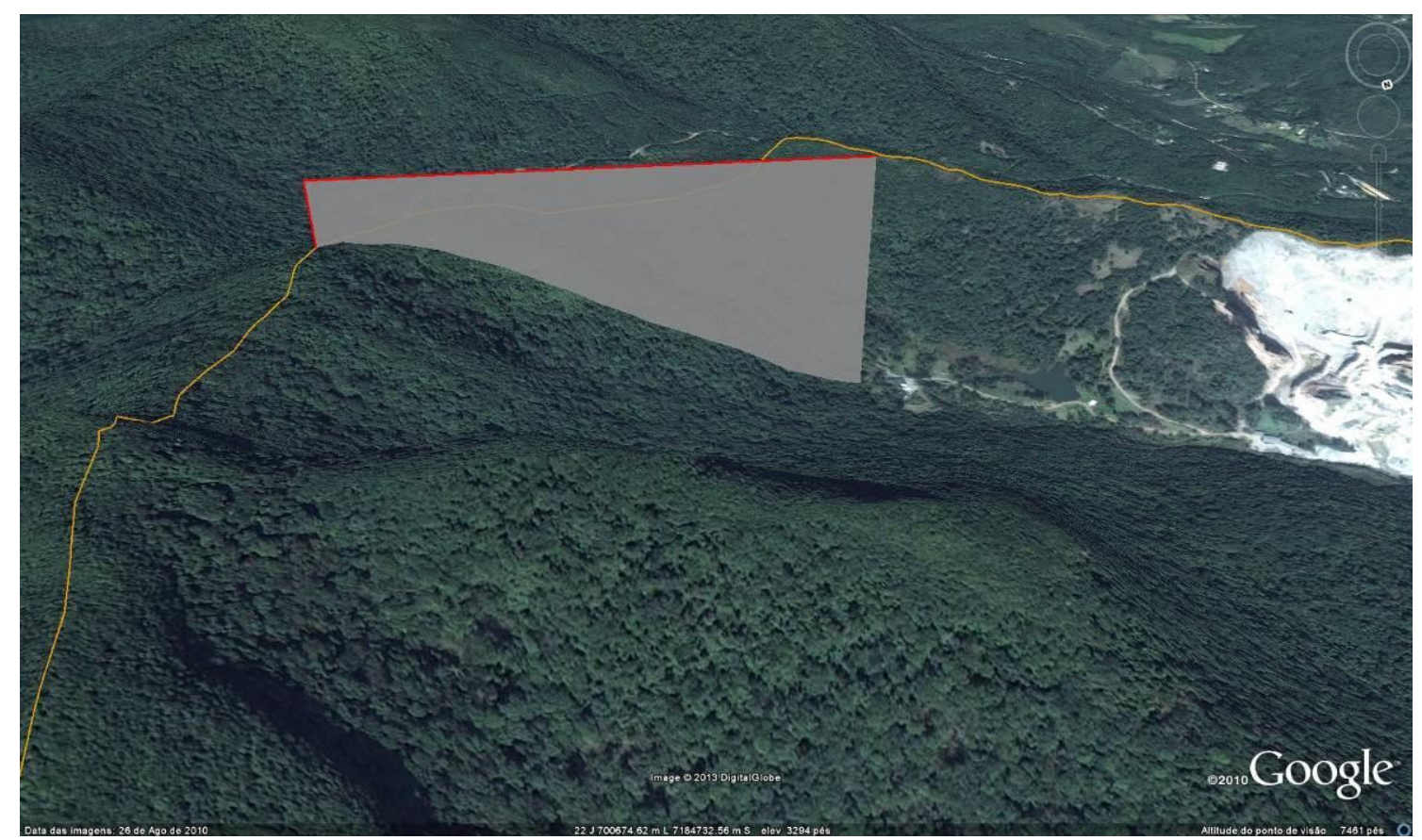

Figura 4 - 'Perfil 2' - Vertente na Bacia do Rio Curralinho

Fonte: Google Earth, adaptado pelo autor.

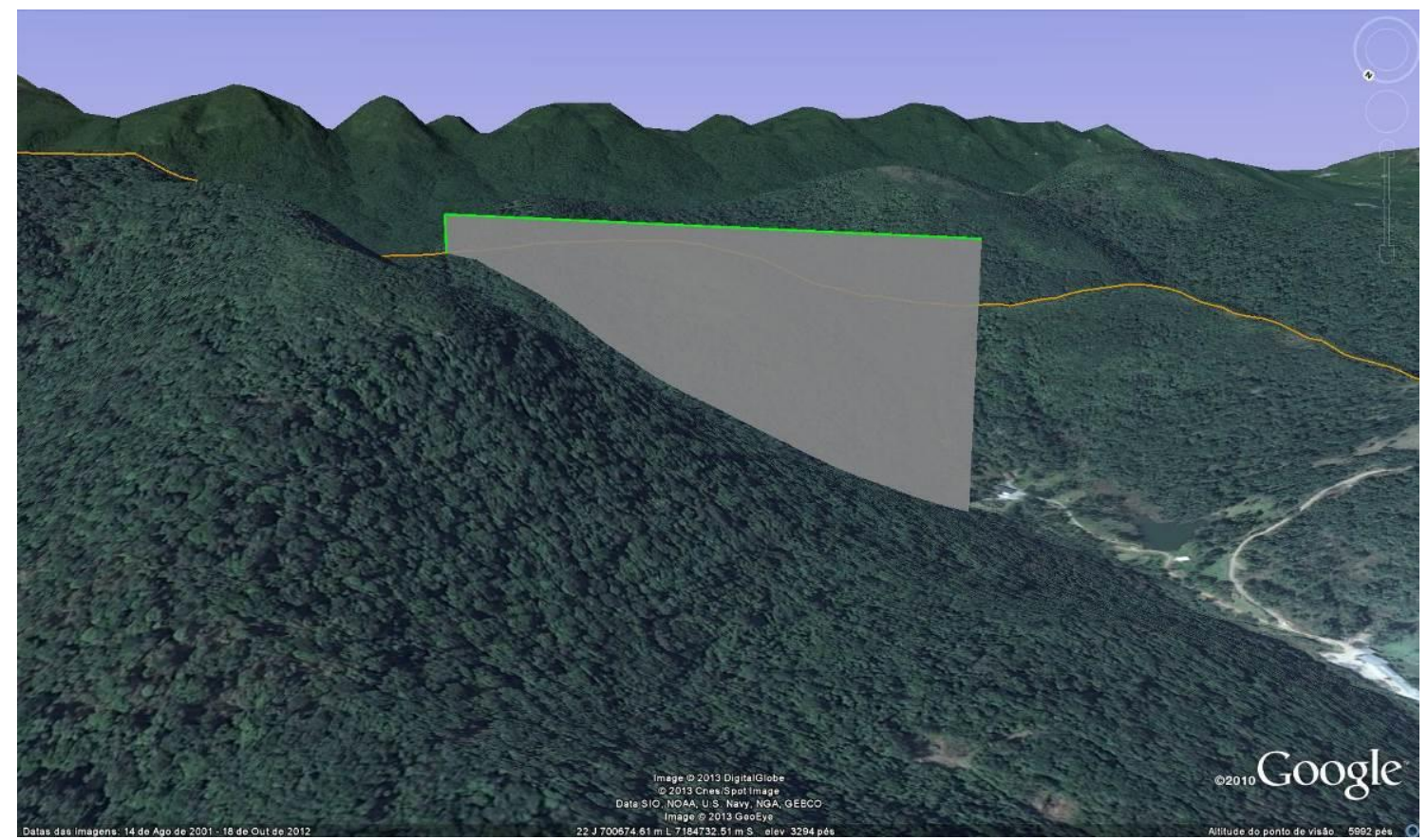

Figura 5 'Perfil 3' - Vertente na Bacia do Rio Curralinho Fonte: Google Earth, adaptado pelo autor.

Tais divergências decorrem da dificuldade de se estabelecer classificações para vertentes (superfícies tridimensionais) a partir de metodologias que 
representam as mesmas via perfis longitudinais (elementos bidimensionais) obtendo-se assim um conflito entre metodologia e conceito.

Neste sentido, a tradução da forma tridimensional por representações bidimensionais normalmente implica em processos subjetivos de generalizações e extrapolações, no sentido de enquadrar conceitualmente partes representáveis da vertente.

Como, em geral, o número de perfis usados para descrever a vertente é insuficiente, são aplicados pelo agente mapeador/classificador generalizações que reduzem a superfície complexa das vertentes a um conceito único e, por vezes, não representativo da mesma, bem como são estabelecidas extrapolações sobre o perfil no sentido de entender que o mesmo é suficiente para definir as formas em análise.

Observa-se que inúmeros perfis traçados sobre as vertentes no sentido de caracterizar suas formas, se desenhados em diferentes direções e com diferentes extensões resultarão em diferentes formas, dificultando o processo de análise das mesmas, conforme demonstrado por Sampaio e Augustin (2008).

Essa limitação metodológica ganha ênfase ainda maior, quando se observa a dificuldade de, sobre bases cartográficas planialtimétricas, definir alinhamentos ideais para representar, a partir das multivariadas geometrias das curvas de nível, as vertentes.

Neste sentido, a metodologia do emprego de perfis demonstra-se mais adequada à análise de segmentos pré-definidos da vertente sob determinados alinhamentos/direções, descrevendo localmente e direcionalmente a geometria das mesmas.

Contudo, vertentes são superfícies tridimensionais formadas por diferentes geometrias, as quais variam de acordo com a direção observada e extensão projetada, sendo sua descrição via perfil, antes de tudo, uma simplificação de sua forma, sob uma, dentre muitas possibilidades de análise e classificação.

Dylik (1968) apud Bigarella et al. (2007) amplia o conceito de vertente associando a noção de processos. Desta forma, apresenta a vertente como um elemento tridimensional modelado pelos processos de denudação atuantes tanto no passado como no presente, representando a conexão dinâmica entre o interflúvio e o fundo do vale. 
A proposta de Dylik (op. cit.) de conceituação da vertente como uma forma tridimensional baseia-se, conforme Christofoletti (1980), na possibilidade de delimitação de três limites bem definidos, sendo estes:

- inferior: local onde os processos genéticos que determinam a natureza da vertente deixam de atuar, o qual excepcionalmente pode ser definido por um rio;

- superior: indica a extensão mais distante e mais alta da superfície de onde provém um transporte contínuo de materiais sólidos para a base da vertente, e;

- interno: limite que confere à vertente a terceira dimensão, sendo constituído pelo embasamento rochoso.

No que se refere ao limite inferior da vertente, Bigarella et al. (2007) complementam a proposta de Dylik (1968), afirmando que esta deve considerar as descontinuidades naturais que condicionam alterações bruscas nos processos atuantes no modelado da mesma.

Dylik (op. cit.) avançou ao associar a noção de processos, no entanto, embora o autor associasse a vertente a uma forma tridimensional, sua tentativa de enquadrar a vertente como tal foi frustrada, pois o limite interno acabou não conferindo a terceira dimensão à vertente.

Conforme já exposto anteriormente, como as vertentes são comumente analisadas em perfil, o limite interno define simplesmente o contato do perfil com o embasamento rochoso, portanto a vertente continua sendo tratada como uma forma bidimensional (Figura 7).

Sendo as três dimensões formadas a partir de três grandezas geométricas: largura, comprimento e profundidade, o que confere o caráter tridimensional à vertente são os limites laterais somados aos limites superior, inferior e interno. 


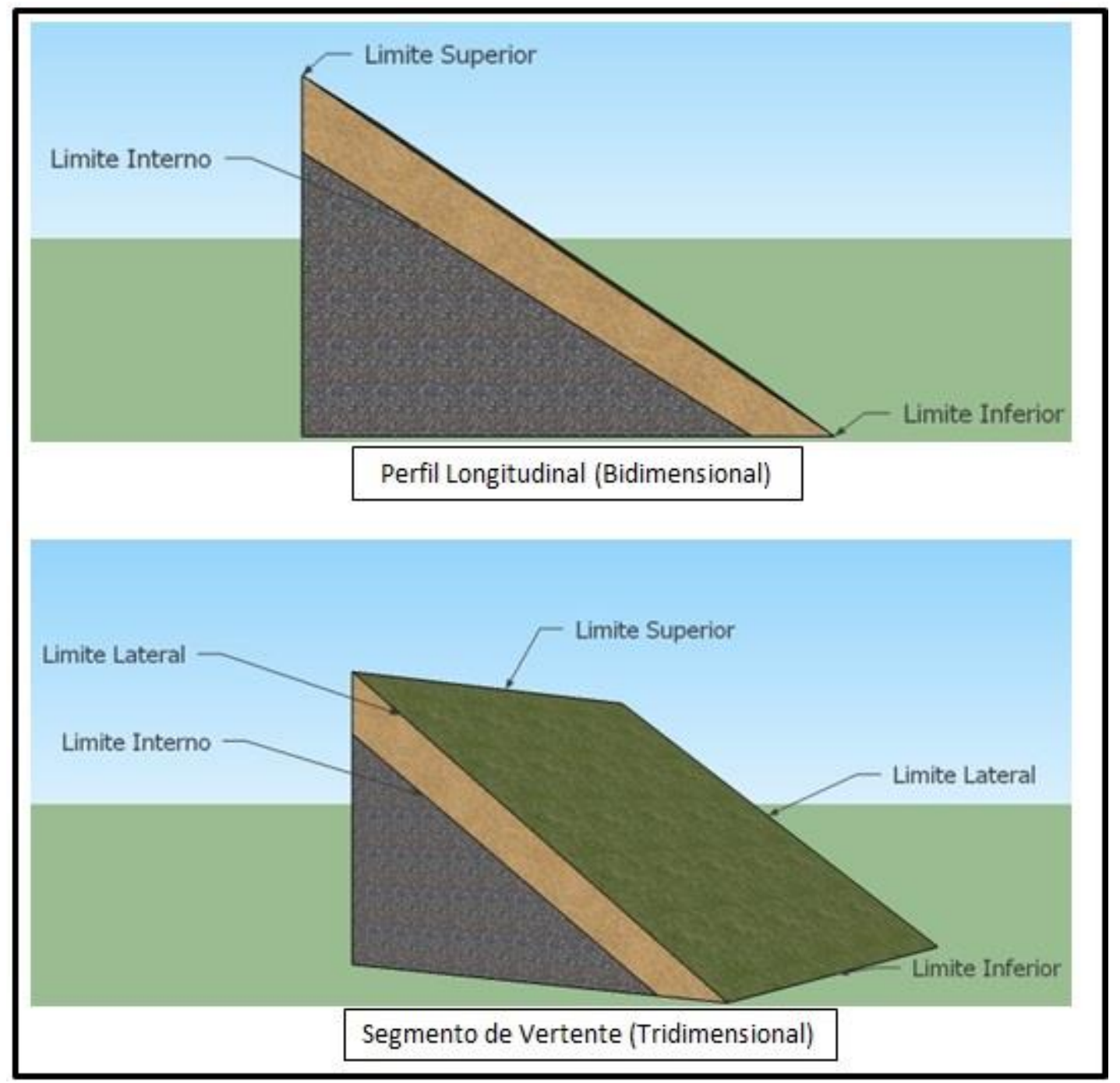

Figura 6 - Vertente em perfil e segmento de vertente em três dimensões Fonte: Organizado pelo autor, 2011.

Dalrymple et al. (1968) consideraram as vertentes como sistemas complexos tridimensionais, que se estendem do interflúvio ao meio do leito fluvial e da superfície do solo ao limite superior do regolito. Os autores dividiram a vertente em nove unidades hipotéticas (Fig 8), cada uma sendo definida em função da forma e dos processos morfogenéticos dominantes e normalmente atuantes sobre ela. 


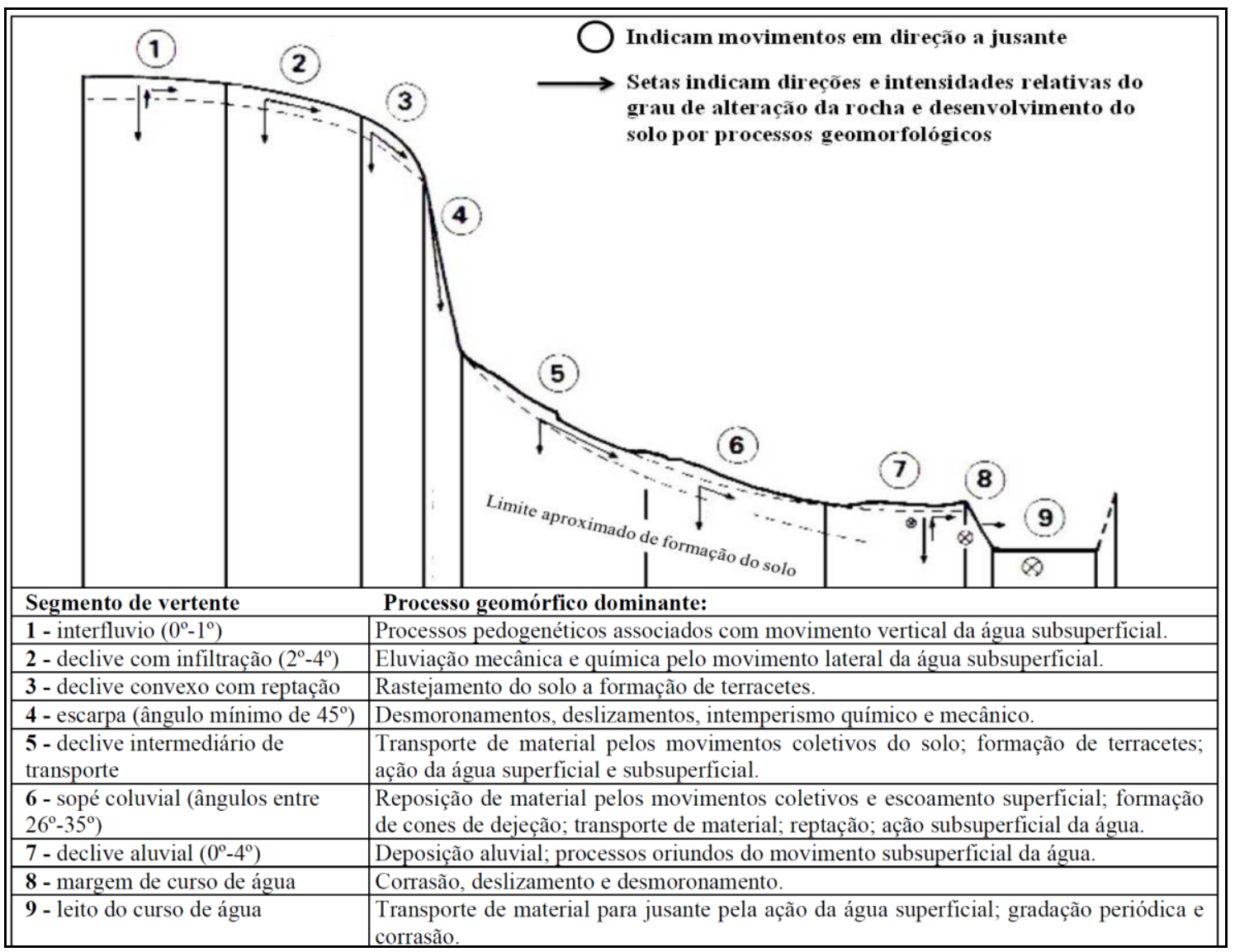

Figura 7 - Nove unidades hipotéticas no modelo de vertente

Fonte: Silveira (2010), adaptado de Darlymple et al. (1968)

A proposta de Darlymple et al. (1968), no que concerne ao caráter tridimensional das vertentes, esbarra no mesmo problema da proposta de Dylik (1968), posto que ao analisar a vertente em perfil, acaba enquadrando-a como forma bidimensional.

Troeh (1965) fez um dos primeiros estudos que considerou a curvatura vertical e a curvatura horizontal, ou seja, tratou a vertente enquanto forma tridimensional, além de associar as vertentes à processos de coleta e distribuição de água, rastejamento e lavagem. O autor classificou as vertentes em quatro tipos principais (Figura 9): vertentes com radiais convexas e contornos côncavos (quadrante I), vertentes com radiais côncavas e contornos côncavos (quadrante II), vertentes com radiais convexas e contornos convexos (quadrante III) e vertentes com radiais côncavas e contornos convexos (quadrante IV). 


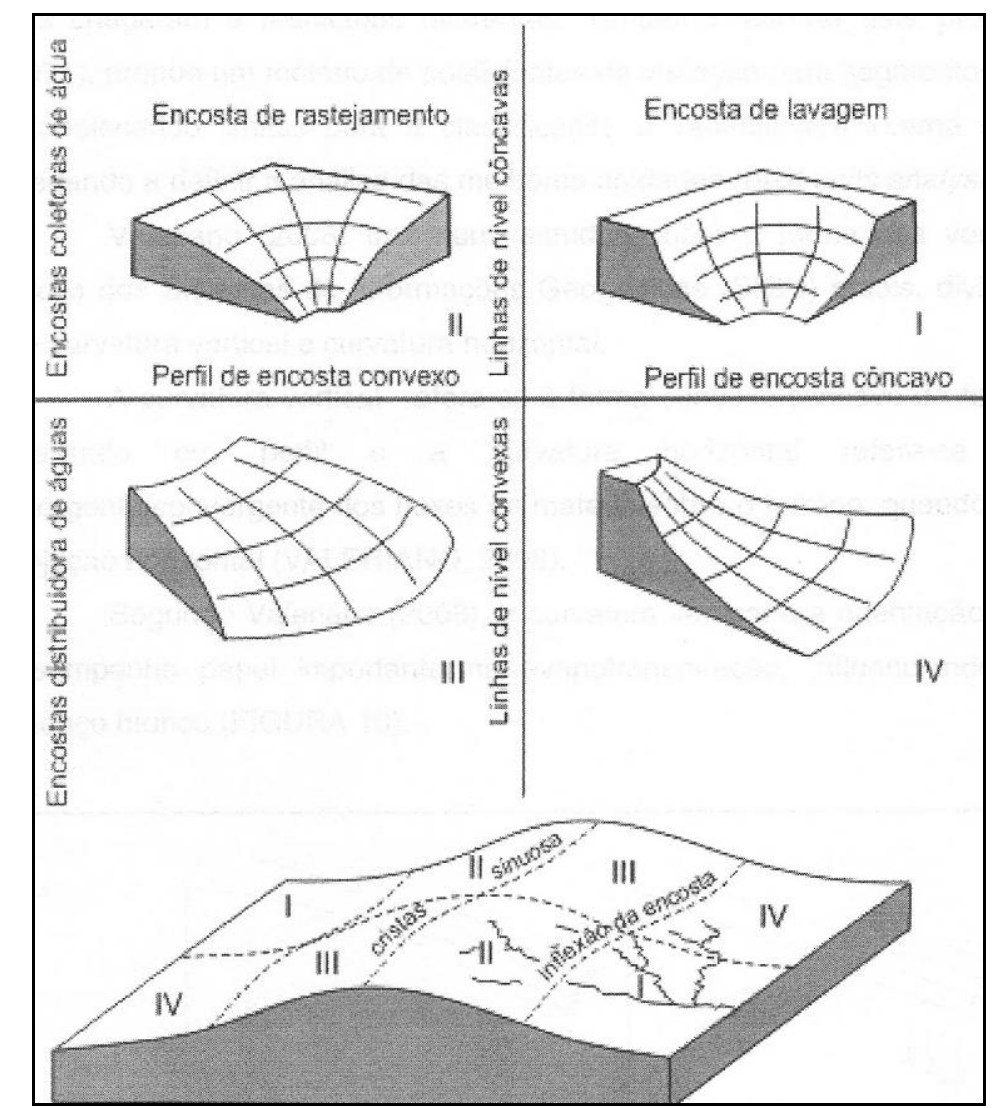

Figura 8 - Quatro tipos básicos de vertentes e os processos atuantes Fonte: Troeh (1965)

Ruhe (1975), ao constatar que as vertentes não podem ser representadas adequadamente por perfis bidimensionais, classificou e conceituou as vertentes como elementos tridimensionais, propondo uma classificação baseada na análise da geometria das formas das vertentes (Figura 10). Nesta, a vertente é o elemento que apresenta segmentos associados de geometrias, formando verdadeiros mosaicos. 


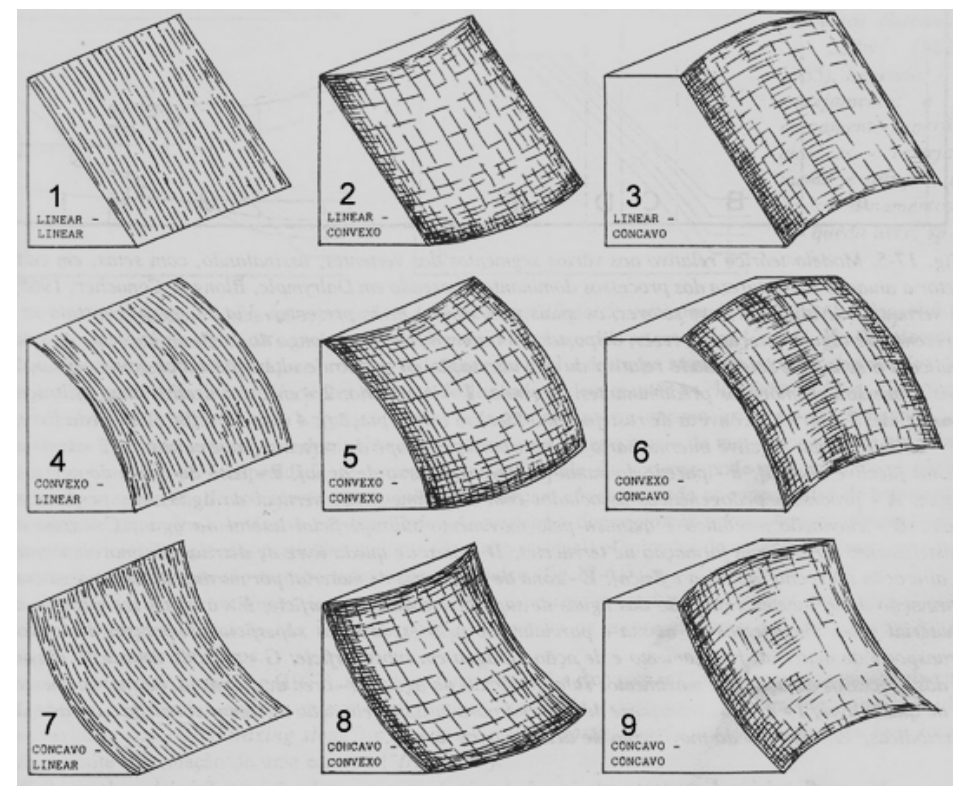

Figura 9 - Geometria das Formas das Vertentes

Fonte: Bigarella, Becker e Santos (2007), adaptado pelo autor.

Com o propósito de verificar a aplicação do conceito proposto por Ruhe (1975), foram classificadas algumas feições de vertentes, a partir de interpretação visual, na Bacia Hidrográfica do Rio Curralinho (Figura 11). Os números (de 1 a 9) referem-se à numeração das feições na Figura 9. As vertentes não foram classificadas completamente, contudo apenas com essas feições identificadas já foi possível perceber o mosaico de formas e a complexidade para aplicação desta metodologia de classificação. 


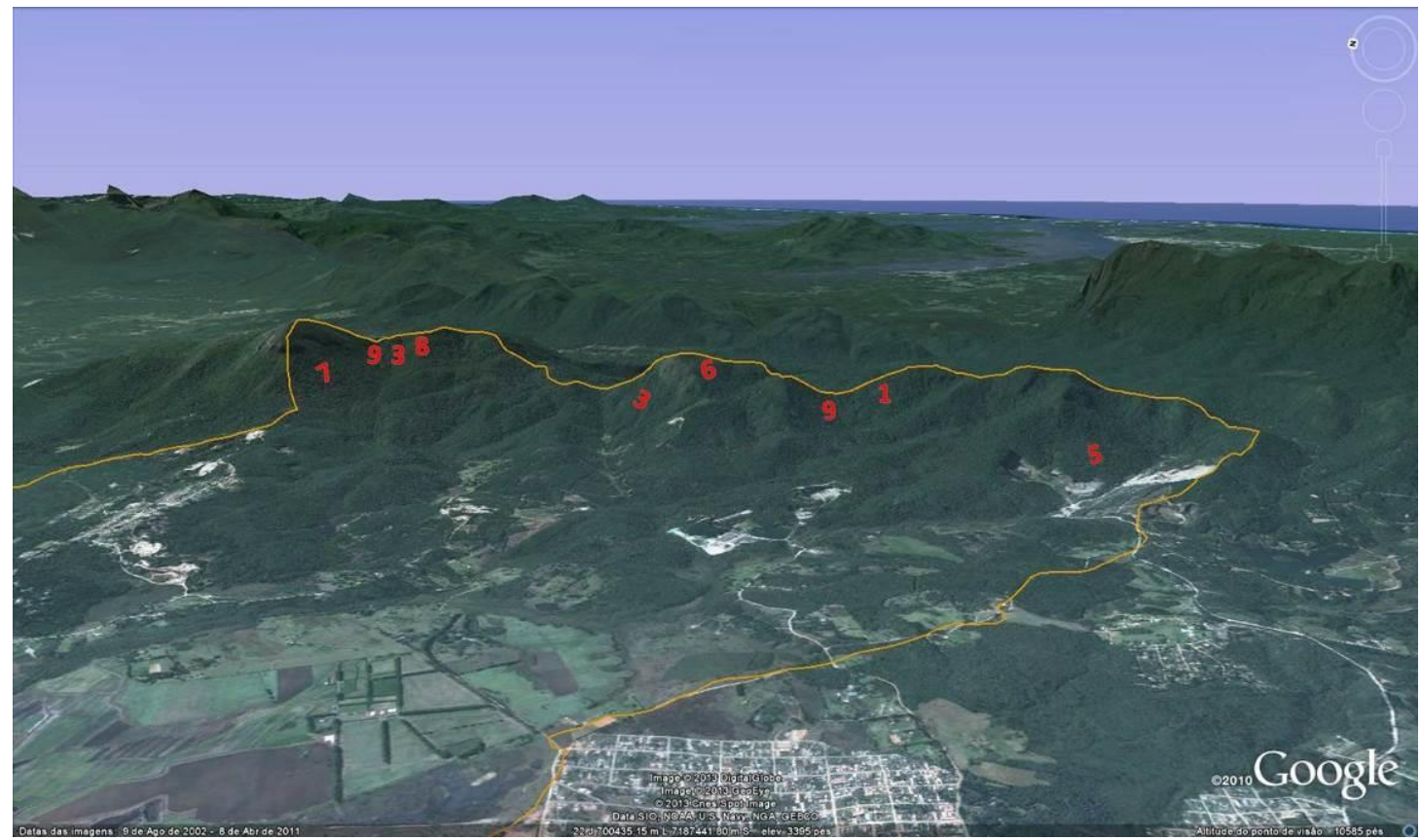

Figura 10 - Vertentes na Bacia do Rio Curralinho com classificação de feições tridimensionais Fonte: Google Earth, adaptado pelo autor.

Florenzano (2008) propôs que, além das três categorias utilizadas no mapeamento utilizado pelo IPT (1981), seja adicionada mais uma para a classificação da forma das vertentes: a forma composta. Esta proposta esbarra na ausência de definição dos limites laterais das vertentes observado tanto para a metodologia baseada em perfis, como naquela proposta por Ruhe (1975).

Cabe observar que, conceitualmente, a proposição de vertentes compostas resulta no enquadramento nesta classe de todas as vertentes a serem mapeadas, visto que inexistem vertentes que apresentem exclusivamente formas retilíneas, convexas ou côncavas, sendo tais formas representativas de segmentos da vertente sob diferentes escalas de análise.

Considerando-se as constatações dos autores acima, infere-se que há incongruências no processo de identificação de formas de vertentes, tanto no que diz respeito aos conceitos, quanto às metodologias, o que pode fazer com que diferentes pesquisadores cheguem a resultados divergentes, mesmo analisando uma única base de dados, conforme já exposto por Young (1971). 


\section{Metodologia}

A primeira etapa do trabalho refere-se à revisão bibliográfica e discussão acerca do conceito de vertentes, bem como seleção dos mapeamentos que foram objetos de análise.

De posse dos dados, o próximo passo foi a extração/vetorização dos polígonos mapeados pelos autores, bem como do limite das bacias.

Utilizou-se o software ArcGIS 9.3.1. Foi efetuada a delimitação do contorno da BHRC e então, de posse da base do Topodata, foi feito um corte nesta, com o auxílio da ferramenta clip, a fim de que a área utilizada fosse restrita à área de estudo.

Em seguida, a partir do banco de dados disponibilizado pelo Instituto Nacional de Pesquisas Espaciais (INPE) no projeto TOPODATA, foi feito a extração dos dados de curvatura vertical para a Bacia Hidrográfica do Rio Curralinho. Cabe salientar que se optou por trabalhar apenas com a curvatura vertical a fim de que os dados possam ser comparados com o mapeamento efetuado por Boiko (2004), que identificou as formas de vertentes somente a partir do perfil de curvatura.

Para representar a variação da distribuição das formas de vertentes, com a utilização do Plano de Informação de Curvatura Vertical discretizado em 3 classes: convexo, retilíneo e côncavo, foi gerado o histograma, disponível na barra de ferramentas do Spatial Analyst, a fim de serem efetuadas as análises necessárias.

\section{Resultados}

Boiko (2004) efetuou um mapeamento de forma das vertentes em perfil de curvatura na BHRC, a partir de fotografias aéreas na escala 1:30.000. Segundo a autora, a fim de estabelecer a fragilidade ambiental da Bacia Hidrográfica do Rio Curralinho, foi necessário transformar os perfis (Figura 12) em polígonos (Figura 13) para que este novo mapa pudesse então ser cruzado com a carta de declividade. Para que essa operação fosse possível, a autora generalizou as formas obtidas a partir dos perfis. 
Estudo de metodologias para identificação de formas de vertentes na bacia do Rio Curralinho - Região Metropolitana de Curitiba/PR

Estipulou-se para o fechamento do polígono que este seria feito com base na forma de vertente de maior predomínio, sendo necessário o mínimo de três vertentes iguais para a formação do mesmo. Quando ocorreram uma ou duas formas apenas de vertentes iguais, estas foram agrupadas ao grupo predominante mais próximo. (BOIKO, 2004, p. 49)

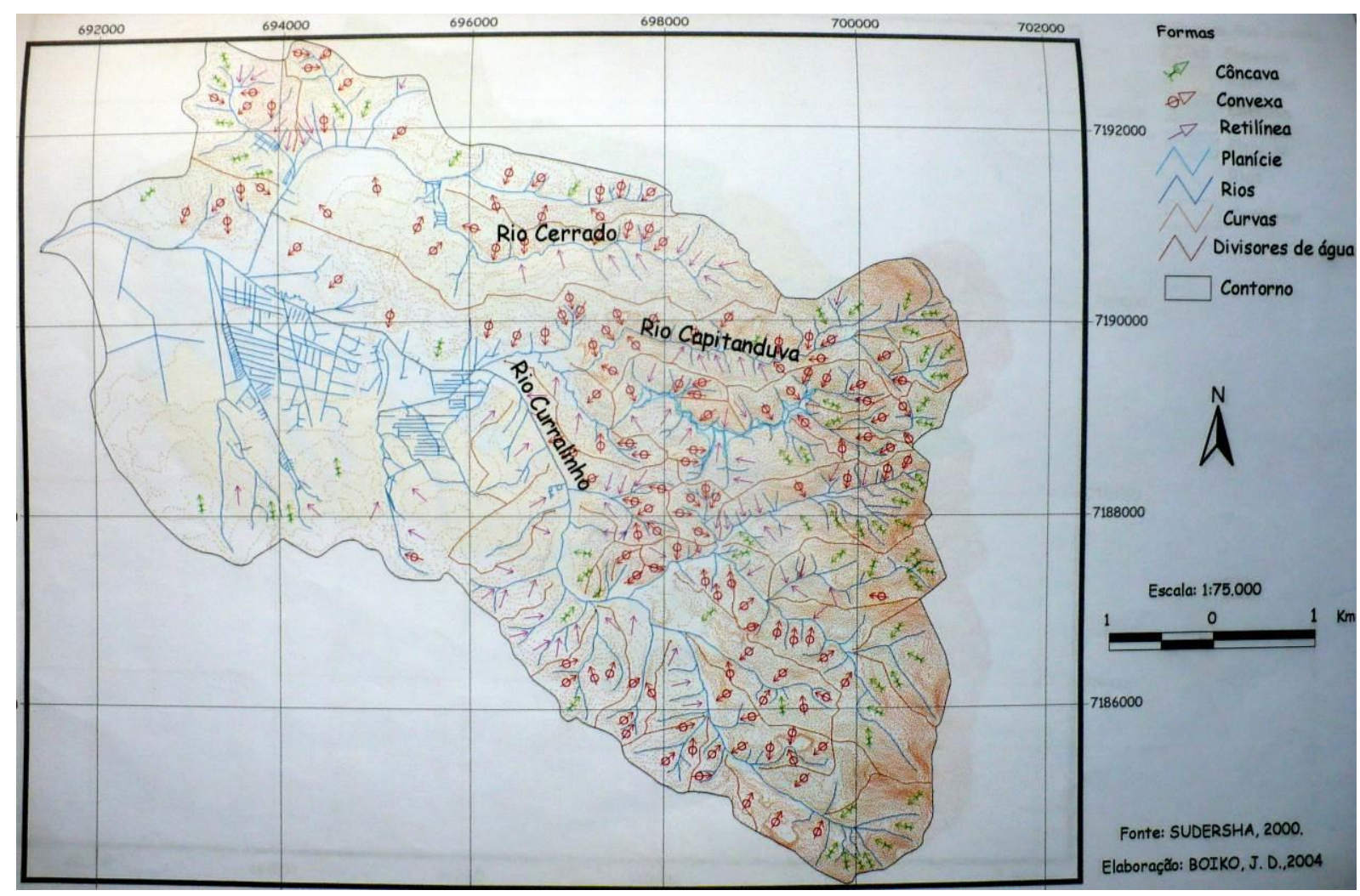

Figura 11 - Vertentes mapeadas em perfis - BHRC

Fonte: Boiko (2004) 


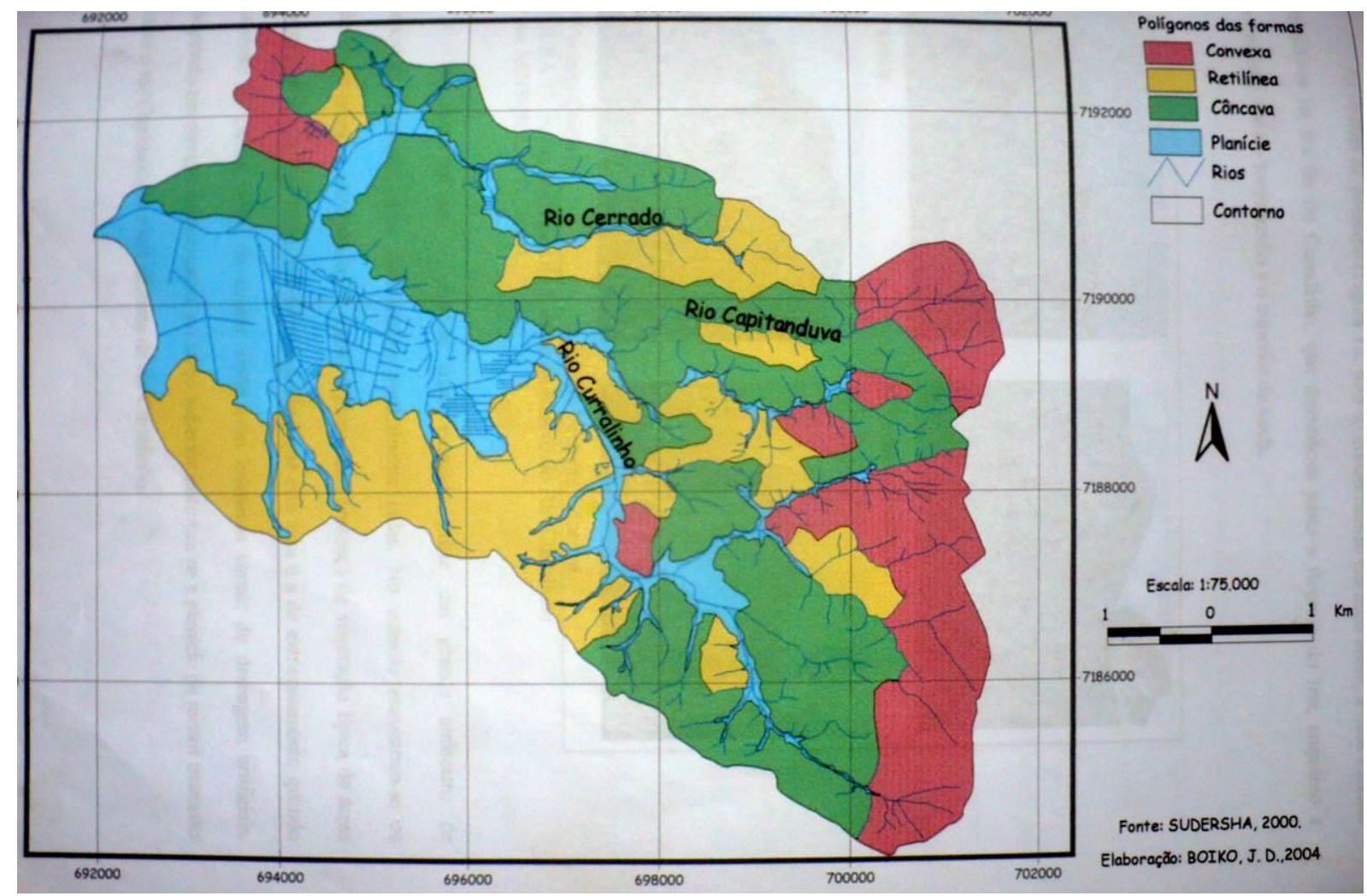

Figura 12 - Vertentes mapeadas em polígono - BHRC

Fonte: Boiko (2004)

A metodologia utilizada pela autora demonstra a carência de parâmetros claros e objetivos na geomorfologia que permitam a classificação das vertentes enquanto estruturas tridimensionais.

É necessário salientar que a classificação feita em perfil por Boiko (2004) (Figura12), acaba sofrendo uma inversão dos valores quando é executada a operação de generalização a fim de enquadrar os perfis em polígonos (Figura 13). Em grande parte da bacia ocorreu uma troca de classificação entre feições côncavas e convexas.

Conforme Boiko (2004), a Bacia Hidrográfica do Rio Curralinho apresenta $24 \%$ de suas vertentes retilíneas, $17 \%$ convexas, $38 \%$ côncavas e $21 \%$ em regiões de planícies (Figura14). 


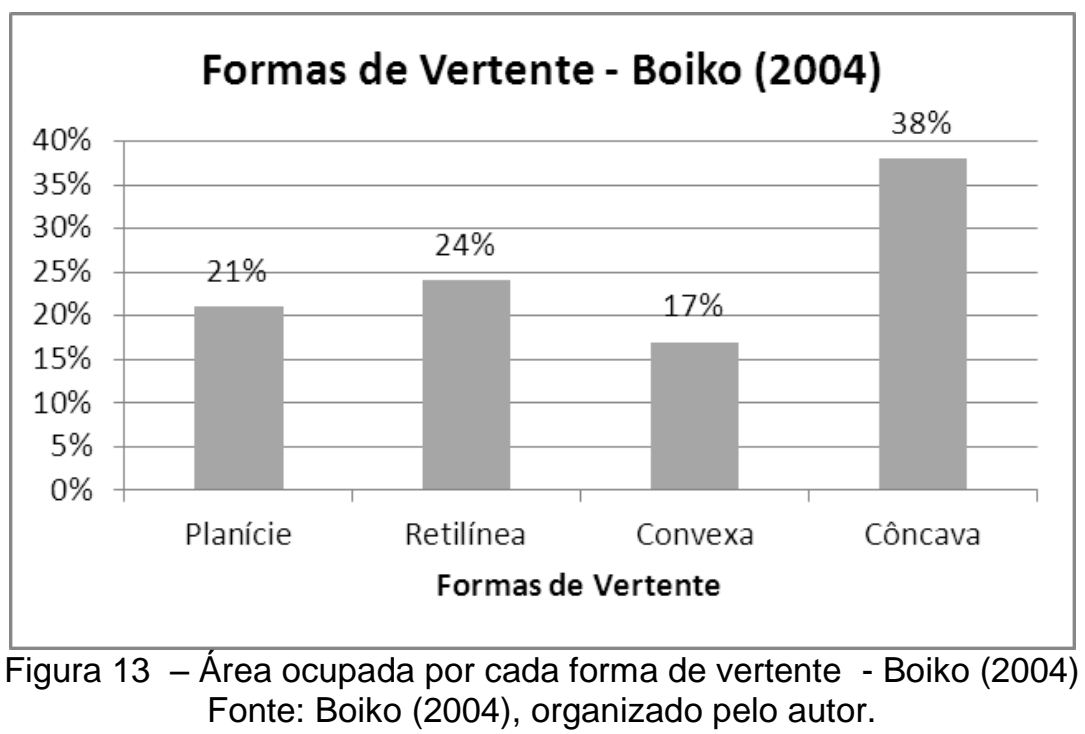

O mapeamento elaborado para a BHRC (Figura 15), de acordo com a base do Projeto Topodata, traz um resultado de identificação de formas de segmentos de vertente, pois mapeia a vertente pixel a pixel.

Os dados do TOPODATA são resultados de uma pesquisa do INPE com vistas à modelagem de dados topográficos do SRTM (Shuttle Radar Topographic Mission). O projeto partiu dos Modelos Digitais de Elevação (MDE's) obtidos a partir dos sensores orbitais do SRTM, com resolução de $90 \mathrm{~m}$.

De acordo com Valeriano (2005), o projeto visou à construção de um banco de dados nacional com elevação e variáveis morfométricas calculado a partir dos dados SRTM disponíveis para o Brasil. O autor afirmou ainda que os MDE's com 90m de resolução passaram por uma melhora na resolução e tiveram redução de falhas.

Os MDE's foram interpolados para uma resolução de $30 \mathrm{~m}$, utilizando-se o processo de krigagem. Segundo Valeriano (2004), a interpolação por krigagem trouxe ganhos sensíveis na qualidade dos modelos, permitindo uma série de aplicações antes prejudicadas por características dos dados originais.

Embora o Topodata aborde a vertente enquanto forma tridimensional (associando perfil e plano de curvatura), optou-se por utilizar nesta pesquisa apenas o mapeamento referente ao perfil de curvatura. Tal fato ocorreu a fim de se poder fazer uma comparação deste mapeamento com o efetuado por Boiko (2004), que mapeou as vertentes apenas com base sem seus perfis. 
Conforme se pode observar, a identificação dos segmentos de vertentes da BHRC, de acordo com a base de dados do Topodata, apresentou o seguinte resultado: $36,65 \%$ das formas de segmento de vertentes côncavas, 35,97\% retilíneas e $27,38 \%$ convexas (Figura 16).

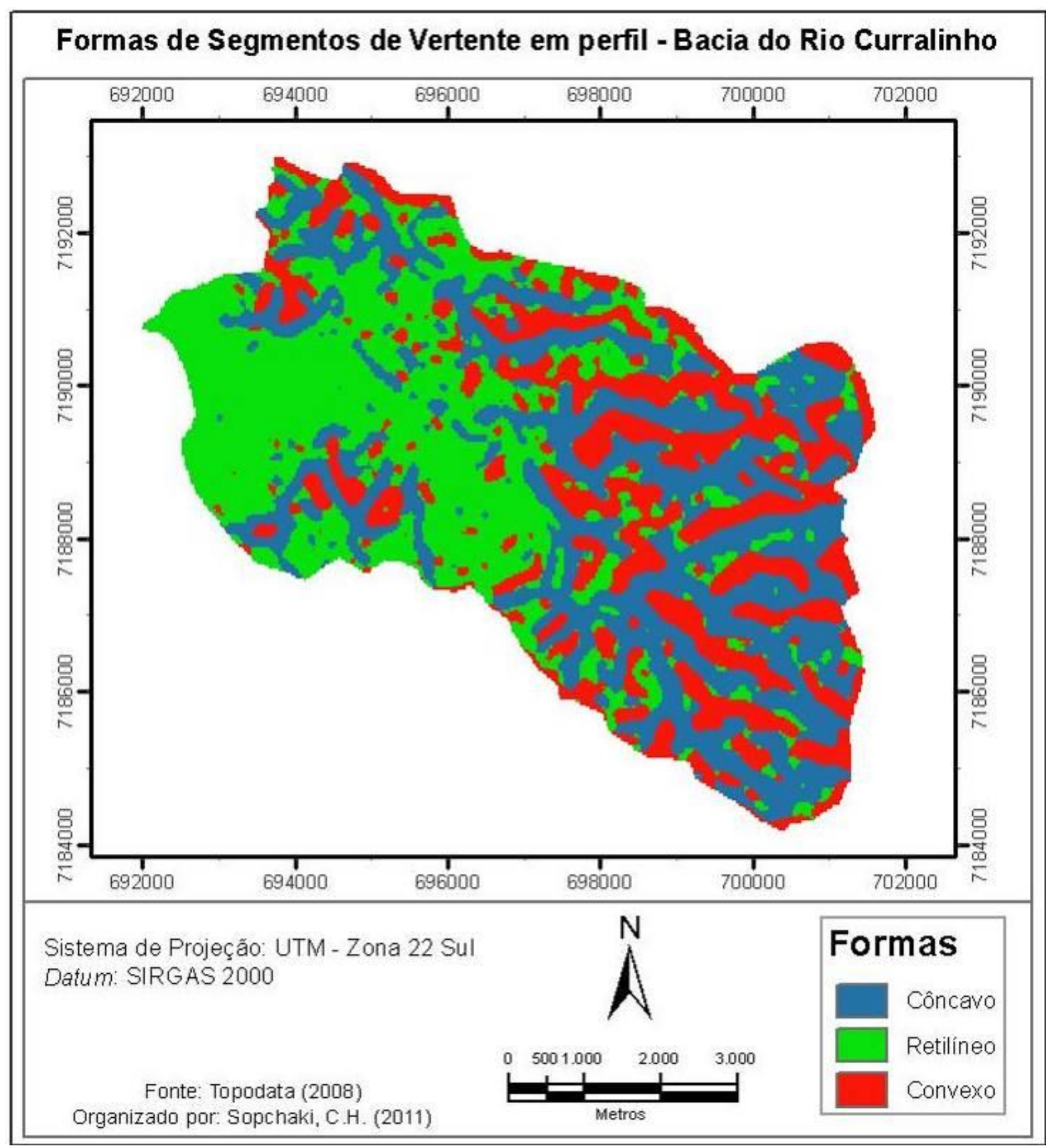

Figura 14 - Mapa de Formas de Segmentos de Vertente em perfil - BHRC Organizado pelo autor, 2011. 


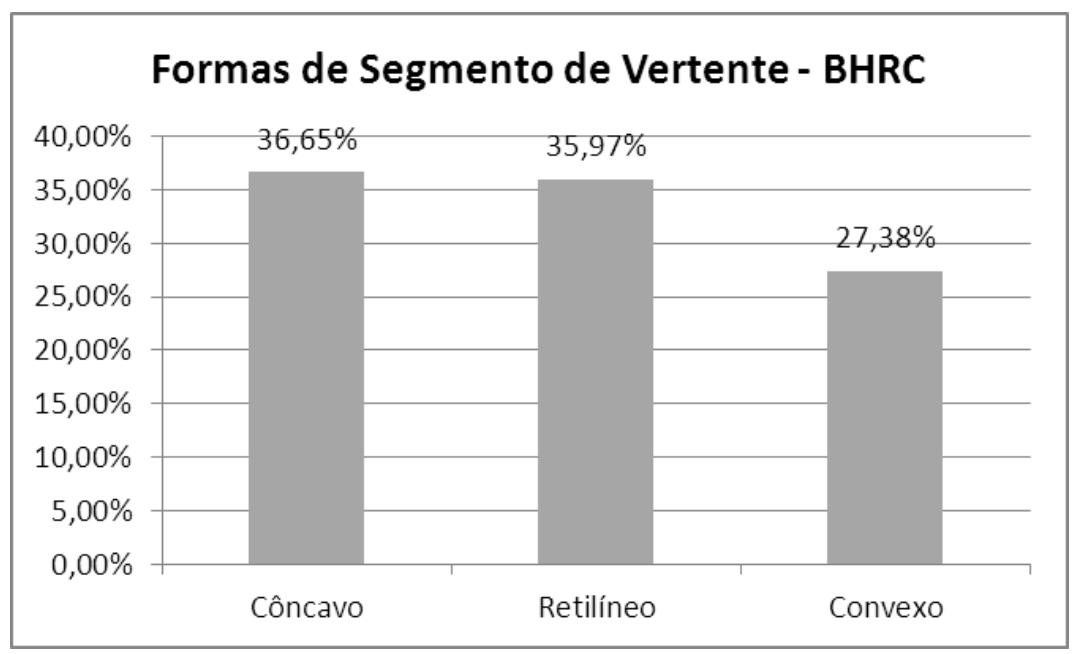

Figura 15 - Formas de Segmento de Vertente (Topodata) - BHRC Organizado pelo autor, 2011.

A análise e comparação dos resultados, em números absolutos, demonstra uma divergência significativa nos valores das classes Retilínea (35,97\% - Topodata; $24 \%$ - Boiko) e Convexa (27,38\% - Topodata; 17\% - Boiko). Destaca-se porém a convergência de valores apresentada na classe Côncava, com 36,65\% no Topodata e $38 \%$ no mapeamento efetuado por Boiko (2004).

No entanto, quando os mapeamentos são sobrepostos (Figura 17), percebese que há grandes divergências na correlação espacial entre todas as classes, incluindo a classe dos perfis côncavos. Portanto, embora o percentual mapeado na bacia como côncavo seja próximo, trata-se apenas de uma coincidência numérica, pois espacialmente os mapeamentos são divergentes. 


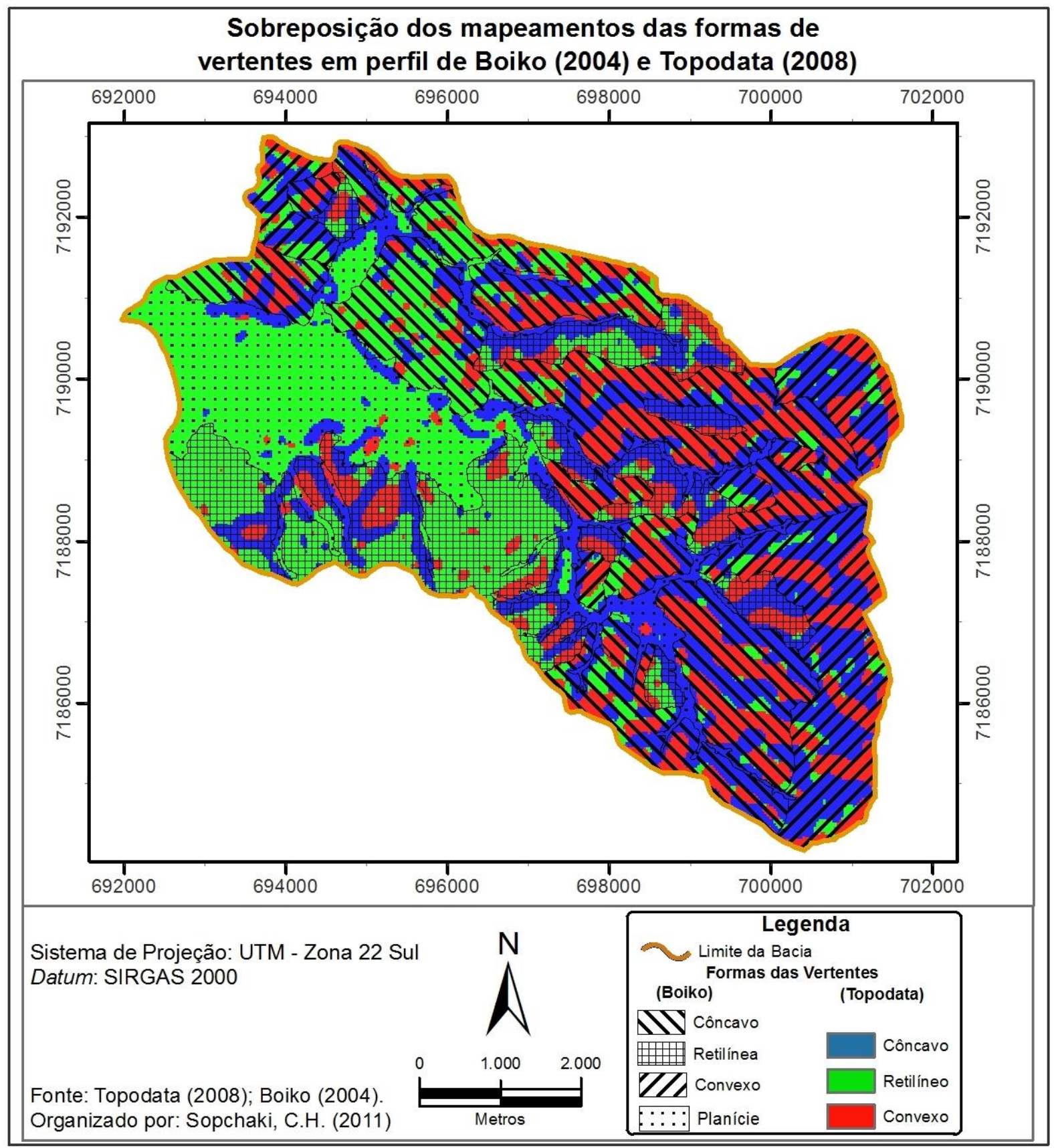

Figura 16 - Mapa de sobreposição dos mapeamentos de formas de vertentes - BHRC Organizado pelo autor, 2011. 


\section{Considerações Finais}

Os resultados demonstraram que não houve consenso entre os dados obtidos a partir do Topodata (2008) e o mapeamento efetuados por Boiko (2004), no que se refere à identificação de formas de vertentes em perfil de curvatura.

Tal discrepância pode ser resultado das diferentes escalas de análise e metodologias aplicadas, como também, reflexos de problemas conceituais e metodológicos que envolvem o conceito e identificação de formas de vertentes.

Boiko (2004) utilizou a técnica de mapeamento utilizando perfis longitudinais bidimensionais, generalizando em seguida os resultados a fim de se obter polígonos. Conforme exposto anteriormente, metodologias como essa, entram em conflito com o conceito de vertente tridimensional.

A identificação de formas de vertentes elaborada a partir da base do Projeto Topodata (2008), por sua vez, leva em consideração o conceito de vertente tridimensional, no entanto ainda não mapeia a vertente como um todo, mas sim segmentos da mesma.

Outra possível interferência nos resultados pode ter sido a inversão de classes de vertentes que ocorreu no mapeamento efetuado por Boiko (2004), na etapa de generalização e transformação de perfis em polígonos.

Levando-se em consideração que a identificação de forma de vertentes é utilizada no planejamento da paisagem através de mapeamentos geomorfológicos e mapeamentos de fragilidade ambiental, há necessidade de estudos mais aprofundados que tragam subsídios e busquem padronizar conceitos e metodologias para que o grau de subjetividade nesse processo seja minimizado.

\section{Referências}

ARGENTO, M. S. F. ;Mapeamento Geomorfológico. In: GUERRA, A. J. T.; CUNHA, S. B. (Org.) Geomorfologia: uma atualização de bases e conceitos. Rio de Janeiro: Bertrand Brasil, 2003.

BIGARELLA, J. J.; BECKER, R. D.; SANTOS, G. F. Estrutura e origem das

paisagens tropicais e subtropicais. 2ª ${ }^{-}$ed. Flortianópolis: Ed. da UFSC, v. 3, 2007. 
BOIKO, J. D. Mapeamento geomorfológico e fragilidade ambiental da bacia hidrográfica do rio Curralinho - Região Metropolitana de Curitiba/PR. Curitiba. 2004. 104 f. Dissertação (Mestrado em Gestão e Análise Ambiental) - UFPR.

CHRISTOFOLETTI, A. Geomorfologia. São Paulo: Edgard Blücher, 2ª Ed., 1980.

DALRYMPLE, J.B.; BLONG, R.J.; CONACHER, A.J. A hypothetical nine unit landsurface model. Geomorphology, Berlin, v. 12, p. 60-76, 1968.

DIKAU, R.; RASEMANN, S.; SCHMIDT, J. Hillslope, Form. In: GOUDIE, A. S. Encyclopedia of Geomorphology. London and New York: Routledge,2006 .

DYLIK, J. Notion du versant en geomorphologie. Translate Title: The concenpt of the slope in geomorphology. Bulletin de l'Academie Polonaise dês Sciences. Series dês Sciences Geologiques ET Geographiques, 1968.

FLORENZANO, T. G. Cartografia. In: FLORENZANO, T. G.; (ORG.)

Geomorfologia: conceitos e tecnologias atuais. São Paulo: Oficina de Textos, 2008.

INSTITUTO DE PESQUISAS TECNOLÓGICAS. Mapa Geomorfológico do Estado de São Paulo. São Paulo: IPT, 1981.

JACOBS, A. G. Dinâmica de uso e ocupação dos mananciais na região metropolitana de Curitiba - PR. Curitiba, 2002. Tese (Doutorado em Engenharia Florestal) - UFPR.

OSTERKAMP, W. R. Annotated Definitions of Selected Geomorphic Terms and Related Terms of Hydrology, Sedimentology, Soil Science and Ecology. Reston, Virginia: Open File Report, 2008.

PENTEADO, M. M. Fundamentos de Geomorfologia. 2a․ ed. Rio de Janeiro: IBGE, 1978.

RUHE, R. V. Geomorphic processes and surficial geology. In: Geomorphology. Boston: Houghton Mifflin Company, 1975.

SAMPAIO, T. V. M.; AUGUSTIN, C. H. R. R. Análise das incongruências dos índices de dissecação e rugosidade. Anais do VII Encontro Nacional de Geomorfologia. Belo Horizonte, 2008.

SANTOS, L. J. C. Pedogênese no topo do Platô de Bauru (SP): o caso da Bacia do Córrego da Ponte Preta. São Paulo. 2000. 183 f. Tese (Doutorado em Geografia Física) - FFLCH - USP.

SAVIGEAR, R. A. G. Technique and terminology in the investigation of slope forms. Premier Rap. De la Comission pour l'Etude des Versants, Rio de Janeiro, 1956. 
SAVIGEAR, R. A. G. The analysis and classification of slope profile forms. L'Evolution des Versants, Liége, França, 1967.

SUDERSHA - Superintendência de Desenvolvimento dos Recursos Hídricos e Saneamento Ambiental. Programa de saneamento ambiental da Região Metropolitana de Curitiba - PROSAN, SIG - para gestão de recursos hídricos do Alto Iguaçu. Curitiba, 2000.

SUMMERFIELD, M. A. Global Geomorphology, an Introduction to Study of Landforms. New York: Logman, 1991.

TOPODATA. Banco de Dados Geomorfométricos do Brasil. INPE, 2008.

Disponível em: http://www.dsr.inpe.br/topodata/.

TROEH, F. R. Landform equations fitted to contour maps. American Journal of Science, v.263, p.616-627, 1965.

VALERIANO, M. M. Modelo digital de elevação com dados SRTM disponíveis para a América do Sul. São José dos Campos, SP INPE: Coordenação de Ensino, Documentação e Programas Especiais; 2004.

. Modelo digital de variáveis morfométricas com dados SRTM para o território nacional: o projeto TOPODATA. Anais XII Simpósio Brasileiro de Sensoriamento Remoto. Goiânia, 2005, p. 3595-3602.

VELOSO, A. J. G. Importância do estudo das vertentes. GEOgraphia, v. 4, n. 8, 2002. Disponível em: http://www.uff.br/geographia/ojs/index.php /geographia/article/view/89. Acesso em: 06 Jul. 2010.

YOUNG, A. Slope Profile Analysis. Zeitrschrift für Geomorphologie, Supplementband, 1964.

Slope profile analysis: the system of best units. In: BRUNDSEN, D. Slopes form and process. London: Institute of British Geographers, 1971.

Slopes (Geomorphology texts; 3). 2a․ ed. New York: Longman, 1972. 